\title{
Interculturalidad y educación popular: un análisis desde las narrativas de estudiantes universitarios ${ }^{1}$
}

\author{
Intercultural and popular education: \\ An analysis from the narratives of University Students \\ LUIS ViVERO ARRIAGADA ${ }^{\mathrm{a}}$ \\ a Trabajador Social, Doctor en Procesos Sociales y Políticos en América latina. \\ Académico Departamento de Trabajo Social, Universidad Católica de Temuco- Chile \\ $\triangle$ luisvive@gmail.cl
}

\begin{abstract}
RESUMEN
El objetivo de este trabajo es identificar y analizar las prácticas educativas que favorecen el diálogo intercultural en el aula de clases en las carreras de la Facultad de Ciencias Sociales de la Universidad Católica de Temuco², de acuerdo a los relatos de los estudiantes mapuche. La metodología consideró un análisis interpretativo de los discursos de estudiantes mapuche, generados a partir de un grupo de discusión, articulado con la perspectiva teórica de Paulo Freire y otros intelectuales latinoamericanos. Los resultados del análisis interpretativo muestran que los estudiantes mapuche, sienten que el espacio socioeducativo, reproduce prácticas colonizadoras. Se concluye que una educación intercultural descolonizada, debe necesariamente sustentarse en una apertura al diálogo intercultural, en términos epistemológicos y teóricos.
\end{abstract}

PALABRAS CLAVE: Educación intercultural; identidad cultural; estudiantes mapuche; colonialismo.

\section{ABSTRACT}

The objective of this work is to identify and to analyze the educational practices that favor the intercultural dialog in the classrooms in the majors of the Faculty of Social Sciences of the Catholic University of Temuco, of agreement to the statements of the students Mapuche.

1 Este trabajo es parte de la investigación titulada "Prácticas Educativas en Educación Superior que favorecen el diálogo intercultural. Experiencias en la Facultad de Ciencias Sociales de la Universidad Católica de Temuco”, la cual está financiada por el Proyecto DGIP.

2 A partir de año 2018, la Facultad cambia al nombre de Facultad de Ciencias Sociales y Humanidades. 


\section{VIVERO}

The methodology was considered an interpretative analysis of the discourses of mapuche students, generated from a discussion group, articulated with the perspective theoretical of Paulo Freire and other Latin American intellectuals. Interpretive analysis results show that mapuche students, feel that the educational space, plays practical colonizing. It is concluded that decolonized intercultural education must necessarily sustain itself an openness to intercultural dialogue, in epistemological and theoretical terms.

KEY WORDS: Intercultural education, cultural identity, mapuche students, colonialism.

\section{INTRODUCCIÓN}

En esta investigación, se ha planteado como objetivo general, identificar y analizar las prácticas educativas que favorecen el diálogo intercultural en el aula de clases en las carreras de la Facultad de Ciencias Sociales de la Universidad Católica de Temuco. En este artículo se abordará particularmente lo generado a partir del grupo de discusión con estudiantes de origen mapuche que durante el año 2016-2017 cursaron alguna asignatura en la cual, en sus contenidos, consideraban temas relacionados con la interculturalidad y el pueblo mapuche. Los cursos seleccionados por carrera fueron los siguientes: "Trabajo Social, pueblo mapuche y praxis intercultural" (carrera Trabajo Social), "Conflicto y negociación” (Ciencia Política), “interculturalidad, ciudadanía y sujetos sociales” (Psicología), Sociedad y pueblo mapuche (Antropología) y en el caso de la carrera de Sociología, el curso es "Sociología de la cultura".

Los análisis que se presentan en este trabajo, se sostienen fundamentalmente desde los postulados de Paulo Freire. Sin perjuicio de lo anterior, también se consideran otros referentes del pensamiento crítico latinoamericano u occidental que aporten a la reflexión y práctica descolonizadora. Desde esta perspectiva, se entiende la educación como una praxis socio-política, eminentemente problematizadora, crítica y emancipadora. En consecuencia, el educar no es un acto individual, ni mucho menos de imponer conocimientos. En una educación crítica "ya nadie educa a nadie, así como tampoco nadie se educa a sí mismo, los hombres se educan en comunión, y el mundo es el mediador" (Freire, 2006, p. 92).

El pensamiento político educativo de Freire, es eminentemente humanista crítico y existencialista. De acuerdo a esto, la educación no puede constituirse en un espacio en el cual se depositan conocimientos de forma mecánica y acríticamente. Como antítesis a esto, se postula a una educación de carácter democrática y progresista, la cual debe comenzar por la superación de la contradicción educador-educando. Esto implica la conciliación de estos polos, de tal manera que en el proceso socio-educativo, ambos se hagan, simultáneamente, educadores y educados (Freire, 2006). 
Se asume este tipo de práctica socio-educativa, como un proceso emancipatorio de los hombres y mujeres, que crean y re-crean el mundo. Desde esta perspectiva humanista y crítica, el proceso educativo debe contribuir a la comprensión de la realidad, de las relaciones entre los que constituyen el mundo material y subjetivo (Freire, 2002a, 2002b, 2006).

\section{ASPECTOS METODOLÓGICOS}

El abordaje metodológico para este estudio, supone concentrarse en el espacio de enseñanza-aprendizaje, considerando las relaciones y tensiones que se generan en el espacio del aula. Se opta por una concepción de carácter hermenéutica crítica como horizonte de compresión e interpretación de las prácticas socio-educativas, contextuales y dinámicas, en la cual los sujetos tanto participantes de dichos procesos, como quienes son observadores de éste, pueden interpretarlos, comprenderlos y transformarlos, en virtud de su relación contextual (Canales, 2002, 2013 a, 2013b, Bourdieu, 2002) En tal sentido, estos estudiantes y sus experiencias los constituyen como sujetos histórico-sociales (Horkheimer, 2003; Marx, 1989, Marx, 2006). En consecuencia, una articulación entre conocimiento y experiencia son los elementos centrales para la interpretación de sus discursos (Ricouer, 2008; Silva, 2005). Por lo tanto, entendemos que la unidad teoría y práctica, se expresa en la síntesis de las vivencias de los sujetos particulares, que permite la comprensión de la totalidad histórica (Freire, 1996, 2002, 2004, 2006; Gramsci, 2006, 2012; Lukács, 2013).

Coherente con lo anterior, se ha trabajado en base a un grupo de discusión, en donde los y las participantes exponen libremente sus experiencias en el proceso educativo, considerando particularmente las relaciones y tensiones que se generan en el espacio del aula. Para la selección de los estudiantes, se convocó a aquellos/as que tuvieran al menos uno de los apellidos de origen mapuche. Para conformar el grupo de discusión se debía contar con al menos un/a estudiante por carrera. Se constituyó el grupo de discusión con cinco estudiantes, el cual quedó conformado por tres mujeres y dos hombres. En base a esta estrategia metodológica, se trabajó sobre sus experiencias significativas como estudiantes mapuche en lo que ha sido su proceso educativo. Se buscó identificar de qué forma, las lógicas de reconocimiento versus la racionalidad moderna occidental, expresada en la colonialidad del saber y del poder (Quijano, 2005), se extienden al aula, particularmente en la relación educador educando (Freire, 2002a, 2002b, 2004, 2006).

Se realizó un análisis articulado principalmente desde los planteamientos de Paulo Freire y la perspectiva decolonial, con los discursos del grupo de estudiantes. Sin perjuicio de lo anterior, se toma también aportes de otros autores que no se ubican en la tradición de pensamiento latinoamericano, pero que, desde una perspectiva de análisis crítico, aportan al objetivo que se plantea en este trabajo. En tal sentido, siguiendo a Van Dijk (1989), la unidad de análisis son los discursos generados en el grupo de discusión. Ello permitió visibilizar las contradicciones y tensiones vinculadas al proceso educativo poniendo énfasis 
en las subjetividades como proceso cognitivo y colectivo de socialización de una vivencia que constituye una expresión simbólica de la totalidad histórica (Baeza, 2000, Lukács, 2013 Ricouer, 2008; Schütz, 2003, 2008).

La codificación de las categorías de análisis, se obtuvo a partir de un proceso de reducción del texto Van Dijk (1989). A partir de ello se construye una matriz de análisis que permitió ordenar el contenido del texto discursivo, de acuerdo a los objetivos del estudio. Se construyen macro-estructuras discursivas, las cuales corresponden a "una representación abstracta de la estructura global del significado del texto" (Van Dijk, 1989, p. 55). Luego se aplica lo que el autor define como macro reglas, que son: a) omitir, b) seleccionar, c) generalizar y, d) construir o integrar, las cuales son una forma de "construcción formal de la deducción de un tema (...)" (Van Dijk, 1989, p. 58). De esto se desprenden las siguientes macroestructuras: 1) Historias socio-educativas, 2) experiencias en la Educación Superior, 3) Educación Superior e interculturalidad, y 4) relaciones interculturales en el aula universitaria. Una vez terminado este proceso, de ordenamiento de los discursos se desarrolló la descripción y análisis interpretativo, del cual en este trabajo lo sintetizamos en un análisis integrado, sin hacer distinción de las macro-estructuras.

En consecuencia, y coherente con el sustento epistemológico y la perspectiva metodológica, es necesario explicitar, que los resultados que se exponen en este trabajo, en ningún caso deben ser considerados para hacer generalizaciones o reglas explicativas. Sin embargo, dan cuenta de experiencias concretas, no sólo en el espacio particular del aula y sus tensiones en el proceso de enseñanza-aprendizaje, sino comprendidos a partir de sus experiencias históricas y culturales. Por lo tanto, son experiencias significativas para la comprensión de ciertos procesos socio-educativos, y en particular, respecto de las relaciones interculturales, más allá de los discursos instrumentales o autocomplacientes. Nos invita a reorientar procesos investigativos, en esta línea, a replantearnos preguntas para generar nuevos conocimientos, fundamentar y enriquecer las prácticas interculturales.

\section{La educación sociopolítica intercultural como praxis emancipadora}

El pensamiento de Paulo Freire, es la expresión latinoamericana de un paradigma humanista crítico, que se sostiene sobre la base de la utopía emancipadora, del sueño de una sociedad más justa, solidaria y sin discriminación. Es la lectura científica crítica de la realidad cotidiana, vivenciada histórica y culturalmente por las clases oprimidas.

El proceso de educación crítica y emancipadora que propone Freire, es en sí misma praxis consiente y concientizadora, que gira en torno a la reflexión del sujeto, sobre su propia capacidad de reflexionar. Ello permite reconocerse como sujeto de su propia transformación, de la transformación de los otros y otras, de la transformación de los y las opresores/as. Así entonces, esta perspectiva resulta pertinente para analizar e interpretar las prácticas vivenciales en los contextos de interacciones cotidianas, entre sujetos que 
presentan diferencias socio-étnico-culturales. Sostenemos como tesis, que, en los diferentes campos sociales, interactúan sujetos con diversas concepciones de mundo, entre ellas, las que provienen de la cosmovisión de los pueblos originarios, por lo que resulta necesaria una educación sociopolítica e intercultural que sustente relaciones de reconocimiento, valoración y respeto a las diferencias socioculturales. La interculturalidad, desde una concepción decolonial y crítica, se hace cada vez más necesaria como estrategia socioeducativa y política, para la mejor convivencia social.

Coherente con la tesis sostenida en las líneas anteriores, nos atrevemos a plantear que habría una interesante conexión epistemológica, política y práctica, entre Interculturalidad y la perspectiva de educación popular de Paulo Freire. Al respecto, nos parece interesante lo señalado por Córdova, en el siguiente fragmento:

Las prácticas interculturales implican un intercambio permanente de relación, comunicación y aprendizaje entre personas, grupos, conocimientos, valores y tradiciones distintas que se orientan a generar, construir y propiciar un respeto mutuo para desarrollar sus capacidades por encima de las diferencias culturales y sociales (Córdova 2010, p. 108).

Este proceso educativo problematizador, requiere necesariamente de una permanente actitud crítica de educadores y educandos. Esto Freire lo describe como "una forma crítica de comprender y de realizar la lectura de la palabra y la lectura del mundo, la lectura del texto y la lectura del contexto" (Freire 2002, p. 52). Ello implica necesariamente, el respeto y la tolerancia a todas las expresiones socioculturales que conviven en la vida cotidiana, en un determinado espacio - tiempo histórico.

Consecuente con lo anterior, la educación popular - como se concibe la propuesta teórica y práctica de Paulo Freire - es una perspectiva holística y una estrategia metodológica, que permite, que facilita, que genera la comprensión crítica de las experiencias cotidianas, situadas social, cultural e históricamente. (Freire, 1996, 2002, 2006). De esta forma, los campos socio-educativos, deberían constituirse como espacios significativos, en los cuales se producen y reproducen valores que propicien la igualdad y justicia social. Sin embargo, las prácticas homogeneizantes sustentadas en la racionalidad occidental moderna, han predominado en los espacios socioeducativos, reproduciendo valores y prácticas ancladas en concepciones colonialistas, fundamentadas en la racionalidad occidental moderna y capitalista. Esto sin duda, contribuye a que en el campo socio-educativo, se reproduzca lo que Freire denominaría una pedagogía del oprimido, con relaciones autoritarias y verticales, que traen consecuencias adversas para el reconocimiento y valoración a las culturas originarias, por cuanto las relaciones sociales que se establecen son de dominación, representadas en la contradicción oprimido/opresor (Freire, 1996, 2006).

Frente a lo anterior, se requiere entender la educación en su forma y fondo desde 
una concepción holística, humanista crítica y sobre todo política. Esto, Paulo Freire lo tenía absolutamente claro, y, en consecuencia, desde su perspectiva no se concibe la educación como práctica neutra, no comprometida, ni apolítica. Por el contrario, la educación popular freiriana, no permite neutralidad. Encarna la utopía, cuya búsqueda cotidiana, requiere de valor coherencia y tenacidad (Freire, 1996, 2004, 2002a, 2002b, 2006). La educación popular, persigue la utopía de la emancipación de los seres humanos, el sueño de una sociedad más justa, más solidaria.

La educación popular, por medio de la superación del sentido común, de la comprensión crítica de la historia, busca la superación de la contradicción oprimido/opresor. Implica por lo tanto, superar cualquier explicación metafísica, determinista, o fatalista de la historia (Freire, 1996). Es un tipo de educación que promueve la reflexión y la discusión valiente de las problemáticas cotidianas y estructurales. Pone en diálogo respetuoso, las diferencias entre unos/as y otros/as. Un diálogo que requiere constantes revisiones, que permita levantar un análisis crítico de los diversos descubrimientos. Esto debe sustentarse en una rigurosidad intelectual, expresada además en "una cierta rebeldía, en el sentido más humano de la expresión; que lo identifique, en fin, con métodos y procesos científicos” (Freire, 2004, p. 85).

Para Freire (1996, 2004), las diferentes formas de discriminación representan una manifestación de la ideología dominante, que debe ser superada. Es la expresión material y simbólica, de la contradicción oprimido/opresor, que se manifiesta en el espacio socioeducativo, en la relación educador/ educando y en las relaciones entre los educandos, a partir de sus diferencias de género, clase y raza (Freire, 1996, 2002 a, 2002 b, 2004 y 2006, Quijano, 2005). De ahí entonces, que la educación popular no puede sino ser concebida como una perspectiva que representa de mejor forma, las posibilidades para el reconocimiento y fortalecimiento de una educación intercultural crítica.

Así entonces, la educación popular articulada con la interculturalidad, lo planteamos como una praxis socioeducativa, impregnada del desafío ético-político, de la superación de la contradicción educador/educando, de la superación de las diversas formas de discriminación y de dominación. Entendida la praxis como "reflexión y acción de los hombres sobre el mundo para transformarlo. Sin ella es imposible la superación de la contradicción opresor-oprimido" (Freire, 2002, p. 51).

La educación popular como paradigma y marco de referencia metodológica para una praxis educativa intercultural, requiere antes que todo, que el educador y la educadora, reconozca desde dónde asume su práctica socio-educativa. Requiere de un necesario proceso de análisis de su ser y quehacer educativos, de su propia historia y de su práctica educativa, que le permita pasar de una conciencia intransitiva a un estado de conciencia crítica (Freire, 1996, 2002 a, 2002 b, 2004 y 2006). Esto permitirá asumir la educación conscientemente como una práctica política, que contribuye en su acción a la superación de las diversas manifestaciones de desigualdad y de discriminación. Implica develar al servicio de qué y de quién realizamos una determinada práctica socioeducativa. 


\section{Algunos antecedentes históricos del Pueblo Mapuche ${ }^{3}$}

Antes de centrarnos en las prácticas socio-educativas, nos parece necesario entregar en términos muy generales, algunos antecedentes históricos, políticos y culturales del pueblo mapuche, que es lo predominante en las relaciones interculturales en la Región de la Araucanía, y el espacio en el cual se enmarca este trabajo investigativo. Al respecto, se puede referir que, hasta mediados del siglo XIX, el pueblo mapuche gozaba de autonomía y en sus territorios el Estado de Chile no tenía jurisdicción (Correa et al. 2005). Un texto de historiadores mapuche, lo expresa de la siguiente manera:

La nación Mapuche hasta el siglo XIX, contó con sus propias estructuras de gobernabilidad, las que permitieron un control efectivo de sus extensos territorios. Los distintos ecosistemas existentes en el país Mapuche, fueron generando una economía de abundancia que no desarrolló grupos o clases privilegiadas en su interior (...) (Marimán, Caniuqueo, Millalén y Levil, 2006, p. 123).

El pueblo mapuche originalmente habitaba, por el norte, desde el Valle del Aconcagua, hasta la Isla Grande de Chiloé, por el sur, llegando hasta la Patagonia de Argentina por el este (Bengoa, 2000; Chihuailaf, 1999; Marimán et al. 2006). Los mapuche resisten la ocupación de España y logran su independencia, la que es reconocida a través de los parlamentos celebrados entre la corona española y las autoridades originarias. Dentro de estos parlamentos, se destaca el de Quilín en 1641 y 1647, y Negrete en el año 1726 (Bengoa, 2000).

Más adelante, ya construido el Estado nación y terminada la Guerra del Pacífico (18791883), se produce la ocupación militar del territorio mapuche, impulsada por los gobiernos chileno y argentino, la cual se llevó a efecto con extrema barbarie, en que se incendiaban las rucas, se mataba y capturaba mujeres y niños, lo que en palabras de Bengoa (1999) representa una de las páginas más negras de la historia de Chile. Este proceso que se le ha denominado eufemísticamente la "Pacificación de la Araucanía”, el cual, amparado por la ley chilena, entre otras cosas, significó la usurpación de tierras, que fueron entregadas a colonos nacionales y extranjeros y a los indígenas se les reubicó en pequeñas reducciones de tierras poco productivas (Aylwin, 2003; Bengoa, 2000).

La política de reducción del pueblo mapuche constituye una práctica de carácter etnocida, ya que no solo representa un despojo de sus tierras, sino que "se trató de un proceso de destrucción de las sociedades mapuche autónomas y de las principales bases de sustentación de su cultura" (Saavedra, 2002, p. 60). En el año 1955 más del 80\% de la propiedad de la tierra se encontraba en manos de los grandes terratenientes, lo que significaba que “aproximadamente 1 millón 700 mil hectáreas estuvieran repartidas en unas 10 mil grandes

Consecuente con la opción epistemológica hermenéutica crítica, en todos los capítulos, se hará referencia a mapuche, tanto en lo singular como plural, que es la forma gramatical del mapudungun. Por ejemplo, el pueblo mapuche o los mapuche. Salvo en los casos de transcripción textual de una cita. 


\section{VIVERO}

explotaciones" (Correa et al. 2005, p. 72). La reforma agraria más importante se desarrolla a partir de las administraciones de los presidentes Eduardo Frei Montalva (1964-1970) y Salvador Allende (1970-1973).

A pesar que tales medidas significaron un avance notorio en materia de legislación favorable al pueblo indígena, no tuvo una continuidad, ya que, tras el Golpe de Estado de 1973, se revierte en muchos aspectos, principalmente en aquellos referidos a la propiedad de la tierra y los derechos ancestrales de los pueblos originarios (Salazar \& Pinto, 1999).

\section{El Pueblo Mapuche y su cosmovisión}

Para el Pueblo Mapuche, la tierra no es sólo un elemento más o un bien del cual se puede gozar de su propiedad. Para los mapuche, el concepto de tierra abarca los lagos, ríos, cielos, el mar y todos los organismos que habitan en aquellos y no remite exclusivamente a la tierra en tanto suelo. Los grandes lonkos ${ }^{4}$ usaban el término futal mapu, es decir, "nuestra tierra toda", para indicar que "la tierra no sólo la constituía el suelo, sino también el subsuelo, las riquezas de las profundidades, los ríos, los bosques y todo lo que en la tierra existe" (Ñanculef, 1989, p. 5). En palabras de Marileo, esto queda expresado de la siguiente manera:

Nuestros antepasados y nuestros ancianos conciben al hombre como parte de la naturaleza e interrelacionado con todos los elementos que lo rodean. Debido a lo anterior, el hombre mapuche es muy respetuoso de la naturaleza. Pide permiso y agradece al Mapun Kuse-Fücha , luego coge sólo lo que necesita, lo justo y necesario (...) (Marileo, 1995, p. 103).

La tierra tiene una importancia fundamental para la construcción de la vida cotidiana del pueblo mapuche, lo cual trasciende más allá de lo material. El Wallontu Mapu, es el espacio donde se concentran todos los elementos de la cultura y de la vida social. En el Wallontu Mapu podemos ubicar tres grandes dimensiones: wenu mapu, nag mapu y minche mapu (ver Fig. 1).

Es en el Nag mapu donde se desarrolla la vida cotidiana mapuche, la relación hombre - naturaleza. El lof es el espacio territorial donde se materializa la actividad cotidiana básica (Mariman et al. 2006).

El Wепи Мари, se ubica en la parte superior de la tierra, que sería para el pueblo mapuche "la tierra de arriba", un espacio sagrado e invisible donde habita la familia divina,

4 Lonko, en mapuzungun o mapudungun, que es la lengua originaria del pueblo mapuche, significa cabeza, por lo cual esta figura es una de las autoridades políticas más importantes de la comunidad, en tanto la machi o el machi, sería la autoridad religiosa del pueblo mapuche.

5 Mapun Kuse-Fücha, la tierra, el anciano y la anciana. Expresa el respeto por la tierra, y por los mayores y sus enseñanzas. 

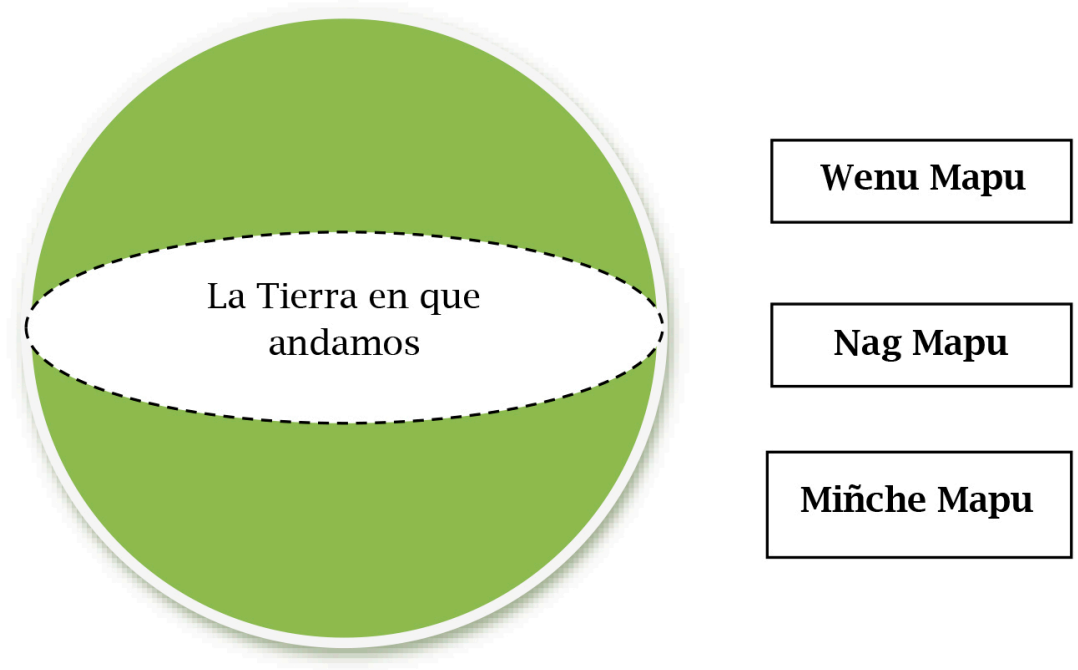

Fig. 1. Representación de la cosmovisión del pueblo mapuche. Fuente: Elaboración propia a partir de la literatura revisada.

los espíritus del bien y los antepasados mapuche. El Miñche Mapu, corresponde el extremo inferior de la Nag Mapu, donde se encuentra la fuerza del mal o espíritus malignos. La contraposición de los dos espacios cósmicos, la Wепи Мари (tierra de arriba) y la Miñche Мари (tierra de abajo), se proyecta activamente en la Nag Mapu (tierra central), lugar de la naturaleza y morada de la gente. Es el lugar del aukan (conflicto) permanente entre las fuerzas antagónicas, en este espacio coexiste también la dualidad necesaria para alcanzar el equilibrio (Chihuailaf, 1999; Marileo, 1995).

En contraste con la concepción espiritual y metafísica expresada en la cosmovisión del pueblo mapuche, se encuentra la legislación del Estado uninacional, que impone la nacionalidad chilena, la cultura occidental y la religión judeo cristiana, y una educación basada en la racionalidad occidental moderna. Con ello, se ignora toda la riqueza e historia cultural, religiosa, social y política de dicho pueblo.

\section{Discriminación y resistencia en la práctica intercultural:}

La experiencia socio-educativa de estudiantes mapuche

En este apartado, se presenta un análisis de los discursos de estudiantes mapuche, los cuales se articulan con los aportes de Paulo Freire y otros intelectuales latinoamericanos. En tal sentido, se encontrarán citas textuales, principalmente de este autor, la cual tiene como objetivo visibilizar con mayor precisión lo que sostiene Freire, y con ello invitar a la reflexión, a repensar la interculturalidad, articulada a la educación popular, como una praxis democratizadora. En cuanto al análisis, éste se ha organizado como síntesis de lo que se desprende de las cuatro macro-estructuras contenidas en los discursos de los/as estudiantes mapuche, lo cual ha sido explicado en el apartado "aspectos metodológicos". Se toma en 
consideración los significados que genera el convivir en un espacio de permanente tensión, entre el conocimiento científico occidental moderno, que es hegemónico y dominante, respecto a la cosmovisión mapuche que los/as estudiantes traen consigo, como parte de sus experiencias familiares, en su convivencia en sus lof, como parte de su kimun.

Por ello, es que resulta fundamental, tener en consideración el apartado anterior referido a los antecedentes socio-históricos y culturales del pueblo mapuche, y mirarlos a la luz de los elementos teóricos-conceptuales y prácticos de la educación popular que nos presenta la extensa producción intelectual de Paulo Freire. Esta articulación nos permite revisar la dimensión material e intersubjetiva de la interculturalidad como un proceso históricamente situado, y, por lo tanto, las tensiones no son simplemente conflictividades particulares, sino que se inscriben en el desarrollo histórico, que va tomando una dimensión específica con el proceso de conquista y colonización europea (Antileo et al. 2015; Dussel, 1973, 2005; Mariman, 2012; Quijano, 2005; Salas, 2003). En tal sentido, la educación como campo material e intersubjetivo en que se manifiestan las contradicciones, la práctica intercultural, no es sino una manifestación de las tensiones histórico políticas y éticas, que dan cuenta de la colonialidad del poder y del saber. Así entonces, la escuela como institución social y campo de poder reproduce formas de control que se inscribirían en la línea de la colonialidad del poder y del saber:

La institucionalidad te ha marcado con nombre, una cierta identidad y una nacionalidad de que no es la tuya, pero que tú tienes que empezar a buscar de dónde eres y cómo te arraigas a eso, si a través de becas, a través de beneficios sociales o si a través de las prácticas culturales (participante 4).

El pueblo mapuche no sería un pueblo oprimido, sino existiera una relación histórica de violencia y discriminación (Aylwin, 2000, 2001; Bengoa, 1999, 2000; Chihualilaf, 1999; Mariman et al. 2006). Tomando a Freire (2002), cabe precisar que los que oprimen son los que instauran la violencia (material y simbólicamente). El pueblo mapuche ha sido despojado de sus derechos como pueblo, lo cual lo grafica muy bien lo que plantea Freire, en cuanto a que, "mientras la violencia de los opresores hace de los oprimidos hombres a quienes se les prohíbe ser; la respuesta de éstos a la violencia de aquellos se encuentra influida del anhelo de búsqueda del derecho a ser" (Freire, 2002, p. 57).

Así entonces, tomándonos de la lectura del texto citado anteriormente, cabe preguntarse ¿cómo podría el pueblo mapuche en tanto pueblo oprimido, ser iniciador de la violencia, si su condición actual es el resultado de la violencia instaurada primero por los europeos y luego por el Estado chileno? En este sentido, una educación que no reconozca estos elementos históricos, y no se sitúa desde esta contradicción oprimido-opresor, solo contribuye a reproducir la violencia simbólica. En un contexto de diversidad cultural, lo primordial es reconocer la historicidad y cultura de sus actores en la realidad cotidiana (Freire, 2002; Hernández, 2007). Realidad que se materializa y subjetiviza en la práctica socioeducativa, 
en el espacio concreto, que puede ser la universidad, la escuela, el aula de clases. La relación cotidiana entre educadores y educandos, la relación entre quienes se reconocen como mapuche y no mapuche. Una relación contradictoria y conflictiva que puede enmascarar una práctica racista y discriminatoria.

Una discriminación significa que algo está haciendo ruido en otra persona, y cuando la identidad mapuche no hace ruido en nada, quizás es más grave aún, no sé, en términos individuales puede ser mejor, en términos de la identidad en sí es peor, no sé (participante 2).

Paulo Freire plantea que "ninguna pedagogía realmente liberadora puede mantenerse distante de los oprimidos (2002, p. 54). En tal sentido, no se podría hablar de una educación intercultural crítica y emancipadora, si esta no busca la reestructuración de las prácticas intersubjetivas discriminatorias, sustentadas y refrendadas por la colonialidad del saber y del poder (Quijano, 2005; Dussel, 2005).

Las demandas de los estudiantes, también se han expresado en los distintos espacios construidos por los estudiantes, en sus procesos de formación y también en torno a sus luchas por una educación pública y gratuita. Ahí también se dieron las contradicciones:

Una concientización política, sociocultural, de cómo digamos conformándose las sociedades en relación a las clases sociales, donde estaban realmente los mapuches dentro de esas clases sociales (...) durante la enseñanza técnico profesional los profesores, no estaban ni ahí con que diéramos la PSU (Prueba de Selección Universitaria) porque nosotros íbamos a seguir siendo campesinos. Luego en el Colegio Claret - colegio particular de la ciudad de Teтuco- todos querían que fuéramos universitarios y que dejáramos de ser mapuches, o eso no importaba, y en el otro extremo en el técnico forestal, van a trabajar en las forestales como obreros (participante 2).

Comenzó la cosa de la reforma educacional, las demandas por la educación y también hicimos que estuvieran esas demandas, pero desde el sector mapuche contemplada, y pero después nos dimos cuenta que estábamos pidiendo al Estado chileno que nos diera lengua mapuche dentro de las escuelas y los liceos, que nos diera religión mapuche dentro de las escuelas y los liceos y que nos (...) al final de que el Estado a través del sistema educacional nos revistiera de nuestra identidad. Después dijimos, "estamos puro tonteando", porque la identidad no se construye en las escuelas, se construye en las comunidades, no tenemos por qué pedirles al Estado o a la escuela que nos enseñe mapuzungun, que nos diga como son los mapuches o que aquí les tengamos que mostrar en un gimnasio cerrado y cosas así, y que lo debemos hacer en la comunidad, así que estábamos puro tonteando (participante 4). 
Estos espacios, permitieron generar un debate y un análisis crítico, un proceso de conciencia crítica, y de solidaridad colectiva, más allá de la sola adscripción étnica. En este sentido la solidaridad, tiene un sentido político, pues, solidarizar con quienes sufren la opresión, quienes son víctimas de la discriminación racial, de género o de clase, es mucho más que conmoverse o prestar apoyo (Freire, 1996, 2002, 2004). Una solidaridad crítica, implica un cambio radical y estructural, es una actitud radical, de transformación material e intersubjetiva. Si no hay un compromiso de un cambio radical, la solidaridad y empatía con los oprimidos, se traduce solo en una práctica contemplativa o caritativa, que enmascara en sí misma una forma edulcorada de opresión, de dominación y de menoscabo a los sujetos oprimidos por su condición de raza, género o clase.

En el caso particular del pueblo mapuche, no es el responsable o causante de la discriminación, por cuanto no es una cultura hegemónica ni dominante. Por el contrario, es víctima de una práctica histórica de dominación y discriminación (Aylwin 2000, 2001; Bengoa, 1999, 2000; Chihualilaf, 1999; Mariman et al. 2006). Lo que genera la ideología discriminatoria no es la cultura discriminada, sino la cultura hegemónica” (Freire, 1996, p. 35).

Aquí se muestra una interesante contradicción entre dos tipos de educación, una que parte de la base que todos son pobres y mapuche, sin mayores conocimientos ni posibilidades de desarrollo, por lo cual la educación, no es más cumplir con un proceso administrativo, donde en última instancia, seguirán siendo pobres y campesinos. Y otra, que espera que todos cumplan las expectativas del establecimiento educacional, que los sitúa dentro de los mejores colegios, por lo tanto, tienen que dejar de ser lo que son, es decir, dejar de ser mapuches y asimilarse e la cultura dominante, ser profesionales universitarios.

Teniendo en cuenta, los cambios socioeconómicos, sociopolíticos y socioculturales, como también los avances tecnológicos (Binimelis, 2017), el principal desafío del sistema socio-educativo, sería orientarse "hacia la construcción de un sujeto comprometido con los principios de ciudadanía, orientado a la comunicación intercultural y concernida en la gestión democrática de la sociedad" (Molina-Chávez, Oliva-Figueroa, 2015, p. 1129). Por lo tanto, en este contexto, dominado por la racionalidad occidental moderna, de carácter neoliberal, "es imposible comprender estas ideologías sin analizarlas y sin analizar su relación con los poderosos y con los débiles" (Freire, 1996, p. 35).

Los/as estudiantes mapuche, los/as no mapuche y los/as académicos/as, tienen una lectura del mundo que puede ser muy distinta, producto de sus experiencias y su cosmovisión expresada en sus distintas prácticas culturales comunitarias. De ahí entonces, que, en el espacio del aula, se produce un encuentro entre culturas y entre saberes, que deben ser valorados, respetados y reconocidos.

En el campo de las prácticas socio-educativas democráticas, el respeto a las diferencias y saberes de las diversas expresiones culturales, es una exigencia ética. Al respecto podríamos articular el desafío de una educación intercultural democrática y progresista, con lo que a continuación nos plantea el autor: "El educador democrático no puede negarse el deber 
de reforzar, en su práctica docente, la capacidad crítica del educando, su curiosidad, su insumisión" (Freire, 2002, p. 27).

Esto implica sin duda una perspectiva ética y política que debe expresarse una relación entre educadores y educandos distinta a aquella que denomina educación bancaria (Freire, 2006). Es una ética que se funda en las prácticas históricas y culturales de los excluidos y sus aprendizajes. Esa ética, la describe de la siguiente manera:

La ética de que hablo es la que se sabe afrontada en la manifestación discriminatoria de raza, de género, clase. Es por ésta ética inseparable de la práctica educativa, no importa si trabajamos con niños, jóvenes o adultos, por la que debemos luchar (Freire, 2002, p. 18).

Por lo tanto, una educación intercultural, es una práctica política que superando la contradicción educador-educando, se inscribe en una permanente relación de diálogo y respecto de los distintos saberes. Un diálogo que no se da en el vacío epistémico y político, sino que, por el contrario, "implica la responsabilidad social y política del hombre. Implica un mínimo de conciencia transitiva, que no se desarrolla bajo las condiciones ofrecidas por el gran dominio" (Freire, 2004, p. 64) Esto contribuye a que los educadores y educandos, se encuentren en un diálogo de saberes.

¿Pero cuál debería entonces ser la actitud de un educador progresista que asuma una práctica académica desde una perspectiva ética intercultural? Freire, nos dice que el educador debe ser ante todo un ser humilde. En este proceso, "el educador democrático no puede negarse el deber de reforzar, en su práctica docente, la capacidad crítica del educando, su curiosidad, su insumisión" (Freire, 2002a, p. 27). Entonces, la humildad debería ser una característica y la actitud del educador frente a los educandos que nos ayuda a reconocer la premisa básica del pensamiento freiriano: nadie lo sabe todo, nadie lo ignora todo. Todos sabemos algo, todos ignoramos algo. Al respecto, dice el autor que:

Sin humildad, difícilmente escucharemos a alguien al que consideramos demasiado alejado de nuestro nivel de competencia. Pero la humildad que nos hace escuchar a aquel considerado como menos competente que no es un acto de condescendencia de nuestra parte o un comportamiento de quien paga una promesa hecha con fervor (...)" (Freire, 2002b, pp. 75-76).

La humildad en esta relación, aportaría a una práctica socio-educativa horizontal, y de respeto a los saberes de los/as educandos. En particular, los saberes que traen consigo los estudiantes mapuche, pero también su forma de leer la palabra, de leer el contexto, de leer críticamente el mundo intercultural el cual interactúan y construyen en su cotidianidad. Nos preguntamos entonces si en las prácticas socio educativas, ¿existe esa humidad, que permita reconocer al otro con saberes, que son distintos a los impuestos por la hegemonía? 
El espacio educativo, es una extensión la sociedad moderna, o sus inconclusiones que la caracterizan como post modernas. En dicho escenario, las diferentes prácticas cotidianas, están mayormente dominadas por la ideología post colonial racional moderna, representadas en el nuevo patrón de poder, y sus diferentes recursos materiales y subjetivos para su preproducción. Así entonces, nos parece difícil que se pueda dar esa humildad de la que nos habla Freire, y que esto se traduzca en una práctica educativa democrática e intercultural.

Desarrollar una praxis intercultural en el campo de las prácticas socio-educativas y en particular en las relaciones entre educadores y educandos, implica necesariamente, enfrentar y superar las divisiones de clase, de raza, y de género. Los/as estudiantes mapuche, cargan consigo una historia marcada por la permanente exclusión e invisibilización de su condición de pueblo, de su memoria, de su cultura, de su cosmovisión. Ello en el espacio de socialización secundaria se refuerza, tal cual lo manifiestan los y las entrevistados/as:

En la básica a nadie le enseñan "que es ser mapuche", y eso es en los colegios sobre todo en la enseñanza media también. ¿Qué se enseña?, se enseña cosas como, quien fue Lautaro (...) se folkloriza (...) forma parte de la cultura, del folclore (...) los 'Mapuches fueron, eran (...) Entonces, fueron así, hicieron esto, de ésta forma vivían, de esta forma trabajaban". Entonces ¿y uno dónde queda?, entonces yo digo que ese incentivo igual es negativo, mezclar el pensamiento mapuche con la modernidad (participante 3).

Y el mismo entrevistado agrega lo siguiente:

Entonces había un curso que estaban todos los urbanos, y de buen promedio, el "A". Y estábamos en otro curso, pero los que veníamos del campo. Entonces esa fue como la primera diferencia en el liceo (participante 3).

Respecto de lo señalado por los estudiantes, Quilaqueo (2012) sostiene que, en Chile, la educación básica históricamente no ha considerado en sus procesos socioeducativos, la cultura y la identidad cultural de los estudiantes pertenecientes al pueblo mapuche. Asimismo - agrega - que tampoco hay una formación intercultural de los/as profesores/as, para que puedan abordar sus clases con pertinencia y respeto a la diversidad cultural. Esto deja de manifiesta la necesidad de repensar las estrategias de enseñanza que atañen a las necesidades particulares de los estudiantes según su cultura. Estas vivencias, no hacen sino fortalecer la resistencia a la cultura dominante, como lo que se puede vivenciar en la relación tensionada, entre el Pueblo Mapuche y el Estado Chile, que pretende homogenizar la cultura, sobre la base de una concepción moderna occidental de sociedad. En palabras de Freire, "la cultura discriminada engendra la ideología de resistencia que, en función de su experiencia de lucha, explica formas de comportamiento ya más o menos indiscriminadamente violentos, o críticamente orientados a la recreación del mundo" (Freire, 1996, p. 35). 
¿Cómo es la experiencia intercultural en la Educación Superior, como experiencia concreta, en la relación educador -educando? Pareciera que se repite lo que viene dado por la cultura dominante. Si bien se pueden instalar espacios de discusión, no siempre dan cuenta de la riqueza cultural que encarna el Pueblo Mapuche, ni tampoco se abre a un reconocimiento que se materialice en formas de organizar el proceso socio-educativo. Veamos, que dicen los y las entrevistado/as al respecto:

Se torna un poco más difícil. No deja de ser una limitante para que tú te puedas desenvolver como Mapuche, porque el autodefinirte y buscarte tu rol, en realidad ser Mapuche, ese es el punto de quiebre súper grande, en la universidad. Por ejemplo, el campo, entre estar aquí, no sé, sentado tomando juguito en una mesa, esto deja de ser todo Mapuche (risas). De partida, estar encerrado en una sala, podríamos haberlo hecho afuera, no sé. Pero por temas de comodidad, no me meto, pero esto ya te dice que estamos en un espacio winka (participante 1).

Nos preguntábamos si las Ciencias Sociales tendrían un significado distinto para que los/ as jóvenes mapuche, se inclinen por estudiar las carreras propias de este campo. Si la opción de estudiar una carrera de las Ciencias Sociales, buscaba un espacio en el cual se pudiese generar algún tipo de dialéctica, entre los mundos occidentales y mapuche. Los discursos, nos lleva a pensar que no necesariamente se permite esta dialéctica, lo cual, más bien genera decepción:

Para mí haber estudiado Ciencia Política ha sido el error más grande (...) pensé que para el mundo occidental (...) podría haber una solución política, es decir en el término de las ideas, para muchos conflictos sociales, en este caso los mapuches. Pero a medida que he pasado los años en la carrera, me he dado cuenta de que en realidad de que la ciencia política y que todo pensamiento occidental no va a solucionar los problemas de los pueblos indígenas, porque se sirven de ellos para seguir en su lógica de expansión (participante 2).

Esta argumentación, se refuerza con un ejemplo, donde igualmente se analiza lo que implica lo intercultural y la cosmovisión del pueblo mapuche:

Un profesor me dijo una vez: "Haz un ideario político para realizar una represa". Entonces le dije "pero profe, de verdad no se puede hacer una represa y no intervenir en los procesos de las comunidades mapuches, porque te vas a encontrar con eso", y me dijo " $y$ como en Machu Pichu, se hizo una represa por dentro de un cerro para que no limitara el turismo, y para que los pueblos indígenas quedarán tranquilos". Entonces le decía que cuando uno rompe un cerro, rompe un montón de cosas intangibles, espiritus, Ngen que se llaman, y que afectan a la comunidad. Y tú cómo explicas eso políticamente. Entonces me dice que es para "el bien común", entonces no estamos nunca hablando del 


\section{VIVERO}

mismo lenguaje, nunca, jamás. Y tampoco la ciencia política o cualquier metodología social, o socialista o que utilizan las ciencias sociales, nunca van a poder complementar o aportar en la continuidad en la relación mapuche-naturaleza o de cualquier pueblo indígena, no lo permite (participante 4).

Como dice Freire, "no puede existir una práctica educativa neutra, no comprometida, apolítica. La directividad de la práctica educativa, que la hace trascender siempre a sí misma y perseguir determinado fin, un sueño, una utopía, no permite su neutralidad" (Freire, 1996, pp. 41-42). Así entonces, lo que dice y hace un profesor en el aula, y su forma de relacionarse con los educandos, responderá más o menos a los intereses de la elite dominante, o estará más o menos comprometido/a con las clases oprimidas, con sus luchas y sus prácticas de resistencia y liberación.

Algunos discursos sobre la experiencia en la educación tanto secundaria como universitaria, dan cuenta de las contradicciones, y las dificultades para una práctica educativa intercultural:

Y yo también creo que las Ciencias Sociales también sufren, del neocolonialismo, por así decirlo, y que efectivamente si reproducen prácticas racistas, pero, sin embargo, como también decía la lagmien, es lo que el individuo puedo hacer frente a eso, y como éste lo toma. Que, si bien no va a existir, no vamos a encontrar un libro de un alemán que nos diga cómo organizar el Pueblo Mapuche, si vamos a encontrar formas de organización que se han probado en otros lados, o ni siquiera que se han probado en otros lados, sino que nos sirve para leernos a nosotros mismos, y ahí (...) hay muchas cosas que hacer (participante 2).

Menos se ha incorporado el tema Mapuche. No hay una bajada, como dices tú, del profesor hacia los alumnos, una intención de incorporar conocimiento de los alumnos mapuches o de compartir experiencias para hacer mejor la metodología dentro del aula, no la hay, personalmente encuentro que no (participante 4).

Por ejemplo, ningún profesor, nunca, o de la carrera a preguntado: “¿Quién es Mapuche? Para que no venga en el We Tripantü”, por ejemplo. Yo generalmente, me he reprobado varios ramos porque he tenido que faltar para el We Tripantü ${ }^{6}$ los días antes, porque en mi comunidad no (...) tengo que hacer muchas cosas antes, en mi rol de mujer Mapuche, no como estudiante ni académica (...)” (participante 3).

$6 \quad$ El We Tripantü, es una de las ceremonias más importante del pueblo mapuche. Se conoce como el "año nuevo mapuche", y es un momento en que se renueva la salida del sol y de la luna. Es la renovación de la naturaleza, es una nueva etapa que comienza. Esta ceremonia se realiza e fines del mes de junio y coincide con el solsticio de invierno. 


\section{INTERCULTURALIDAD Y EDUCACIÓN POPULAR}

Si muere alguien, uno tiene que entrar al entierro, y son una semana o cinco días de velorio y funeral, y (...) todo un ritual inmenso y tú no le vas a decir al profe, tú no le puedes decir al profesor, si tú tienes una prueba, si tú vas a un funeral que dura cinco días (participante, 1)

El año pasado me tocó un examen final de ramo, para un Nguillatün. Y yo le dije a la chica que, hacia clases, "sabes que no puedo venir a exponer, no puedo porque tengo un nguillatün”, “„pero a qué hora es?, a las tres - le dije - pero ven a la once - me dijo -”, pero es que no se puede. Uno está inmersa en los tiempos culturales, son distintos a los tiempos académicos, entonces no puedes, no se puede complementar. Ahí no había una intención, por parte del Director este caso la Facultad, de coordinar esos tiempos (...) Y eso nos afecta e incluso como para identificarnos como mapuches, porque si yo no llego a un entierro, dicen: "(...) como ella no entró al entierro. Cuando se le muera a alguien de su familia nadie va a entrar al entierro porque ella no entró” (participante 4).

Acá en la Universidad Católica existe una organización (...) Estudiantes Mapuches UCT, que están organizados, y ellos pidieron a través de formalidades, ciertos protocolos que se piden en estos círculos, en estas instituciones, el tema del We Tripantü. No fueron escuchados, ni una de las peticiones fue escuchada, tomadas en cuentas. Entonces, por una parte, "organícense" para que sean, para que puedan tomar un espacio dentro de todo este, en el poder. Pero cuando se hace, no tiene mayor relevancia en realidad" (participante 2).

Estas contradicciones y dificultades, se dan a partir del choque entre dos formas de concepciones del mundo y de las relaciones sociales y culturales, tanto en el plano material como subjetivo. Para los/as estudiantes mapuche, que traen consigo un acervo de saberes, de kimun, no les resulta fácil, ni sano, que ello sea avasallado por el discurso dominante, sustentado en un saber, en una racionalidad occidental que se impone como única, como superior a otros saberes. Esto parece ser una tensión permanente, aunque no siempre sea enfrentada, pues las relaciones de poder, también se manifiestan en las relaciones intersubjetivas que se da en el contexto de la sala de clases. Las experiencias que relatan los/as estudiantes, son apenas una muestra del choque cotidiano entre dos mundos, dos racionalidades, que se construyen en la dialéctica de educador/educando, pero más bien, desde una concepción de educación bancaria.

Así entonces, si solo se mirase lo que significa para el/la mapuche la vida en la comunidad, en el lof, se tendría en cuenta lo muy importante que es para ellos/as este espacio de convivencia, de desarrollo, producción y reproducción cultural y espiritual (Antileo, Cárcamo-Huechante, Calfío y Huinca-Puitrin, 2015, Chihuailaf, 1999). Es ahí donde se construye toda la vida cultural y religiosa, la comunidad es la base social en el pueblo Mapuche. El lof, "es un espacio territorial 
básico, en que se asentaba una agrupación humana mapuche, demarcando su base territorial, de acuerdo a códigos propios de la cultura y la cosmovisión (Ñanculef, 1994, p. 8). Entonces, si esto, en términos muy básicos, no es entendido por los/as profesores, y no se generan las condiciones para que los/as jóvenes mapuche mantengan su cultura y su vinculación con su territorio, no es posible hablar de una educación intercultural. Por lo tanto, la lógica de una educación bancaria, autoritaria, va a estar más presente en este tipo de prácticas, e incluso se naturaliza como lo que debe ser en el contexto de una educación universitaria. Es decir, lo que se requiere para ser un buen profesional, para tener éxito, es el dominio del conocimiento occidental moderno, y no estos saberes folklóricos. Mientras no se supere esta asimetría, es difícil, hablar de prácticas interculturales, sino apenas de reconocer un multiculturalismo.

Si los profesores y profesoras, no entienden la importancia, el significado político y espiritual que tiene para un mapuche, participar de su comunidad, de sus ceremonias, no hay praxis intercultural. Y los discursos de los estudiantes, nos están mostrando aquello. Hay una rigidez, de desarrollar la práctica educativa, sobre parámetros, exigencias y metodologías occidentales, que más bien refuerzan la colonialidad del poder y del saber occidental moderno. Los discursos de los y las estudiantes mapuche reafirman, que la práctica educativa intercultural, aún no se logra instalar en la educación chilena:

Yo siento que siguen la misma continuidad que se sigue en la básica, que se sigue en la media, lo que tenemos de nuevo en las universidades, hay como un comportamiento que no va a cambiar o no sé cuándo va a cambiar o ¿somos los estudiantes mapuches responsables de que esto cambie? Eso es lo que yo sacaría de las aulas y es una responsabilidad compartida por nosotros" (participante 3 ).

\section{Y agrega:}

Diría que tampoco hay como respeto de repente, al referirse a algunas temáticas que son de nosotros, nuestras. Por ejemplo, cuando ocurren hechos de violencia, o muere una persona en una comunidad, hay, uno escucha muchas cosas cuando viene a sentarse, cierto, a la sala de clases y el profe te habla y te habla" (participante 3).

Yo creo que no existe una sensibilización de verdad. Porque es un problema de la educación en general, los profesores también fueron educados por otros profesores y que no generaron esa calidad, esa apertura de un conocimiento por un respeto (participante 2).

En las palabras del Rector está la palabra interculturalidad, y eso lo escuchado y lo he leído (...) el discurso está, es un discurso, pero no se genera una acción. Yo pienso que no sé, que las palabras no son ingenuas, van dirigidos y los profesores, que quieren hacer pequeñas modificaciones en esos términos, están bien limitados (participante1). 
Siguiendo a Molina y Oliva (2015), lo que plantean los/as estudiantes mapuche, da cuenta de una construcción de identidad cultural, y de práctica cultural, que si bien, viene fortalecida por sus relaciones familiares, se enfrenta a una lógica occidental colonial moderna (Dussel, 2005; Quijano, 2005) en las experiencias desde la educación primaria. Es decir, "los sentidos y procesos de construcción de identidad de jóvenes en espacios escolares, pueden comportar elementos centralizadores y emergentes de las prácticas subjetivas de participación política en el ámbito educativo en específico, y en el campo de "lo social" en general" (Molina \& Oliva, 2015, p. 1126). En tal sentido, los discursos de los y las estudiantes mapuche, no hacen sino, dar cuenta de sus procesos experienciales y de sentidos, respecto del espacio socioeducativo en el cual se habla de interculturalidad, pero que aún no se logra experimentar en la subjetividad de los educandos mapuche. Más bien, pareciera que la interculturalidad es más bien un discurso instrumental, y no responde a una práctica educativa crítica e intercultural, que permita la construcción de conocimientos y proyectos socio-políticos a partir de los saberes provenientes de la cultura mapuche. Estos conocimientos, deben ser no sólo interculturales, sino que deben ser emancipadores, como lo postula Paulo Freire, y también es planteado por los estudiantes y los diferentes referentes del pueblo mapuche.

\section{CONCLUSIONES}

Teniendo de fondo este marco referencial, se articula una reflexión crítica en relación a la práctica socio-educativa de carácter intercultural. Se busca aportar a la discusión teórica y práctica en relación a la acción educativa en contexto de diversidad sociocultural. En tal sentido, la educación popular sustentada en los postulados freirianos, consideramos que posibilita una lectura crítica del proceso socioeducativo en la una sociedad hegemonizada por la racionalidad colonial moderna y postmoderna.

La lectura crítica de las prácticas socioeducativas, que nos ilumina la perspectiva freiriana, permite encuentros teóricos entre la concepción emancipadora de la educación popular y la práctica educativa en un escenario de diversidad intercultural y, por otro lado, posibilita le generación de una propuesta de educación intercultural sustentada en la perspectiva humanista crítica que propone Paulo Freire.

Se ha planteado la educación popular, como marco de referencia metodológica para una praxis educativa intercultural, lo cual requiere antes que todo, que el educador y la educadora, reconozca desde dónde asume su práctica socio-educativa. Pero nos queda la duda, si efectivamente están dadas las condiciones tanto simbólicas como materiales (institucionales), para que los educadores asuman libremente su condición de actor ético político, y en este sentido, transparentes ante sí mismos y con sus educandos, desde donde y como están entendiendo una práctica intercultural, más allá de la sola diferenciación étnica.

Los discursos de los estudiantes mapuche, dan cuenta que la educación sigue siendo un espacio de colonización política y epistemológica. Por lo tanto, se plantea que una educación 


\section{VIVERO}

descolonizada, debe necesariamente sustentarse una apertura al diálogo intercultural, en términos epistemológicos y teóricos, y no solo un reconocimiento de las diferencias étnico -culturales. Esto implica un acto político, no basta con cambiar metodologías, para que una actividad académica en la sala de clases resulte más didáctica. Debe darse una horizontalidad en el proceso de educación, en donde los saberes que traen los estudiantes mapuches, también sean fuentes de conocimientos y sean reconocidos como tales.

El que los estudiantes mapuches, hoy estén en la universidad no ha significado que la dominación epistemológica y política esté superada. En el proceso de enseñanza, y las prácticas educativas en la Educación Superior no hacen sino reproducir la racionalidad occidental moderna, sus lógicas de dominación y control, propias de la colonialidad del poder y del saber.

Por último, consideramos que, una práctica socio-educativa, desde una perspectiva de educación popular, contribuiría a generar una relación de comunicación y aprendizaje intercultural en condiciones de mayor simetría, legitimidad mutua, reconocimiento y valoración de cada saber.

\section{REFERENCIAS}

Antileo, E., Cárcamo-Huechante, L., Calfío, M., \& Huinca-Puitrin, H. (2015). Awükan ka kuxanka zugu Wajmapu mew. Violencias coloniales en el Wajmapu. Temuco: Ediciones Comunidad de Historia Mapuche.

Aylwin, J. (2000). Materializaciones y conflictos: Aplicación de la Ley Indígena en el territorio mapuche (1994-1997) (1a. ed.). Temuco: Instituto de Estudios Indígenas.

Aylwin, J. (2001). Los conflictos en el territorio mapuche: antecedentes y perspectivas. En J. Aylwin (Ed.), Políticas Públicas y Pueblo Mapuche (pp. 25-55). Temuco: Instituto de Estudios Indígenas.

Baeza, M. (2000). Los caminos invisibles de la realidad social. Ensayo de sociología profunda sobre los imaginarios sociales. Santiago de Chile: Editorial Ril.

Bengoa, J. (1999). Historia de un conflicto: El Estado y los mapuches en el siglo XX. Santiago de Chile: Planeta; Ariel.

Bengoa, J. (2000). Historia del pueblo mapuche: (Siglo XIX y XX). Santiago de Chile: Editorial Lom.

Binimelis, H. (2017). Gobierno electrónico como tecnología de inclusión social. Reflexiones desde el Trabajo Social. Revista Katálisis, Florianópolis, 20(3), 448-457.

Bourdieu, P. (2002). El oficio de sociólogo: presupuestos epistemológicos. Buenos Aires: Siglo Veintiuno.

Canales, M. (2006). Metodologías de investigación social. Introducción a los oficios. Santiago de Chile: Editorial Lom

Canales, M. (2013a). Escucha la escucha. Análisis e interpretación en la investigación cualitativa. 
Santiago de Chile: Editorial Lom.

Canales, M. (2013b). Investigación social. Lenguaje del diseño. Santiago de Chile: Editorial Lom Córdova, G. (2010). Diálogo sobre interculturalidad. Revista ISSES, 7, 97-112. Recuperado de: file://C:/Documents\%20and\%20Settings/admin/Mis\%20documentos/Downloads/ Dialnet-DialogoSobreInterculturalidad-3777552\%20(1).pdf

Correa, M., Molina, R., \& Yáñez, N. (2005). La Reforma Agraria y las tierras mapuches. Chile 1962-1975. Santiago de Chile: Editorial Lom.

Chihuailaf, E. (1999). Recado confidencial a los chilenos. Santiago de Chile: Editorial Lom.

Dussel, E. (1973). América latina, dependencia y liberación. Buenos Aires: Fernando García Cambiero.

Dussel, E. (2005). Europa, modernidad y eurocentrismo. En E. Lander (Comp.), La colonialidad del saber: eurocentrismo y ciencias sociales. Perspectivas latinoamericanas (pp. 41-54). Buenos Aires, Argentina: CLACSO.

Freire, P. (1996). Política y educación. Buenos Aires: Editorial Siglo XXI.

Freire, P. (2002a). Pedagogía de la autonomía: saberes necesarios para la práctica educativa. Buenos Aires: Editorial Siglo XXI.

Freire, P. (2002b). Cartas a quien pretende enseñar. Buenos Aires: Editorial Siglo XXI.

Freire, P. (2004). La educación como práctica de la libertad. Buenos Aires: Editorial Siglo XXI. Freire, P. (2006). Pedagogía del Oprimido. Buenos Aires: Editorial Siglo XXI.

Hernández, V. (2007). Colonialidad y poscolonialidad en Europa y América Latina. Apuntes y glosa de un seminario con Santiago Castro-Gómez. Revista Athenea Digital, 11, 149160.

Lukács G. (2013). Historia y conciencia de clases. Buenos Aires: Editorial R y R.

Marimán, P., Caniuqueo, S., Millalén, J., \& Levil R. (2006). j...Escucha, winka...!. Cuatro ensayos de historia nacional mapuche y un epílogo sobre el futuro. Santiago de Chile: Editorial Lom.

Marileo, A. (1995). "Mundo mapuche". En L. Citarella (Comp.), Medicinas y Culturas en la Araucanía (pp. 91-107). Santiago de Chile: Editorial Sudamericana.

Molina, W., \& Oliva, I. (2015). Interfaces complejas en políticas educativas y de juventud: sentidos e identidades. Revista Latinoamericana de Ciencias Sociales, Niñez y Juventud, 13(2), 1125-1140.

Ñanculef, J. (1989). El concepto territorial en el pueblo mapuche. Nütram, 5(4), 5-9.

Saavedra, A. (2002). Los Mapuche en la sociedad chilena actual. Santiago de Chile: Editorial Lom.

Quijano, A. (2005). Colonialidad del poder, eurocentrismo y América latina”. En E. Lander (Comp.), La colonialidad del saber: eurocentrismo y ciencias sociales. Perspectivas latinoamericanas (pp. 201-246). Buenos Aires: CLACSO.

Quilaqueo, D. (2012). Saberes educativos mapuches: Racionalidad apoyada en la memoria social de los kimches". Atenea (Concepción), 505, 79-102. 
Ricouer, P. (2008). Hermenéutica y acción de la Hermenéutica del texto a la hermenéutica de la acción. Buenos Aires: Prometeo.

Saavedra, A. (2002). Los Mapuche en la sociedad chilena actual. Santiago, Chile: LOM.

Salas, R. (2003). Ética intercultural. (Re) Lecturas de Pensamiento latinoamericano. Santiago de Chile: UCSH.

Salazar, G., \& Pinto, J. (1999). Historia Contemporánea de Chile II. Actores, identidad y movimientos. Santiago de Chile: Editorial Lom.

Schütz, A. (2003). Estudios sobre teoría social. Buenos Aires: Amorrortu.

Schütz, A. (2008). El problema de la realidad social. Buenos Aires: Amorrortu.

Van Dijk, T. (1989). La ciencia del texto. Barcelona: Paidós.

Codificación Entrevistas:

1. Peñi Participante1: Hombre, 23 años de edad, proveniente de la comunidad de Tricauko, comuna de Ercilla, estudiante de Trabajo Social.

2. Peñi Participante2: Hombre, 27 años de edad, estudiante de Ciencia Política.

3. Lagmien Participante3: Mujer, 29 años de edad, estudiante de Ciencia política.

4. Lagmien Participante4: Mujer, 25 años de edad, y soy del sector Refue de Padre Las Casas, y estudio acá Ciencia Política.

5. Lagmien Participante5: Mujer, 26 años estudiante de Sociología. 